\title{
Critérios de movimentação na carreira de professores da educação básica em doze capitais brasileiras ${ }^{1}$
}

\author{
Criteria of movement in the career of teachers of basic education in twelve \\ brazilian capitals \\ Criterios de movimiento en la carrera de profesores de la educación básica en \\ doce capitales brasileñas

\section{MARGARITA VICTORIA RODRÍGUEZ DALVA VALENTE GUIMARÃES GUTIERRES JORISMARY LESCANO SEVERINO}

\begin{abstract}
Resumo: O texto focaliza os critérios de movimentação na carreira docente de 12 capitais brasileiras, com base em estudo documental. As carreiras dos professores analisadas apresentam particularidades, como critérios de movimentação na carreira diferenciados, com destaque para a titulação na movimentação vertical e o tempo de serviço, a avaliação de desempenho para a progressão horizontal. A movimentação na carreira é condicionada por fatores tais como os limites orçamentários, bem como o não cumprimento das normas legais que regulam a carreira por parte dos governantes.
\end{abstract}

Palavras-chave: política educacional; plano de cargos e carreira; valorização profissional.

Abstract: The text focuses on the criteria of movement in the teaching career of 12 Brazilian capitals, based on a documentary study. The analyzed careers of teachers present particularities as differentiated criteria of career movement, with emphasis on qualification in vertical movement and time of service, performance evaluation for horizontal progression. The movement in the career presents factors like the budgetary limits, as well as the non-compliance with the legal norms that regulate the career on the part of the rule.

Keywords: educational politics; career and position plan; professional valuation.

Resumen: El texto trata de los criterios de movimiento en la carrera docente de 12 capitales brasileñas, con base en estudio documental. Las carreras de los profesores analizadas presentan particularidades, como criterios de movimiento en la carrera diferenciados, con destaque para la titulación en el movimiento

1 Agradecemos a colaboração dos professores que compuseram a Força Tarefa sobre Planos de Carreira na primeira fase da Pesquisa "Remuneração de professores de escolas públicas de educação básica: configurações, impasses, impactos e perspectivas”: Dalva Valente Guimarães Gutierres, Márcia Jacomini (SP), Vera Brito (MG, in memoriam), Rogério Gurgel (PB) e Fabrício Carvalho (PA) ao disponibilizar o Relatório da FT. 
vertical y el tiempo de servicio, la evaluación de desempeño para la progresión horizontal. El movimiento en la carrera está condicionado por factores tales como los límites presupuestarios, así como el no cumplimiento de las normas legales que regulan la carrera por parte de los gobernantes.

Palabras clave: política educativa; plan de cargos y carrera; valoración profesional.

\section{INTRODUÇÃO}

O presente artigo é resultado dos estudos e pesquisas realizadas no âmbito do projeto de pesquisa nacional "Remuneração de professores de escolas públicas da Educação Básica no contexto do FUNDEB e do PSPN”' (2012-2017), que teve como um de seus objetivos analisar os Planos de Cargos e Carreiras da Educação Básica em 12 estados brasileiros ${ }^{2}$ e suas capitais. Neste trabalho, focalizam-se os 12 municípios das capitais dos estados pesquisados: Florianópolis, Porto Alegre, São Paulo, Belo Horizonte, Cuiabá, Curitiba, Campo Grande, João Pessoa, Teresina, Natal, Belém e Boa Vista, na perspectiva de descrever e analisar os critérios de movimentação na carreira de professores adotados por esses municípios-capitais no contexto do Fundo de Manutenção e Desenvolvimento da Educação Básica e de Valorização dos Profissionais da Educação (FUNDEB) e do Piso Salarial Profissional Nacional (PSPN).

A problemática deste artigo está orientada pelas seguintes questões: por um lado, visa-se a identificar e analisar as normas legais que regulamentam a elaboração e implementação dos Planos de Cargos e Carreiras dos professores da Educação Básica e, num segundo momento, procurou-se verificar como os planos de Cargos e Carreira dos municípios selecionados na pesquisa contemplam as regulações previstas na legislação nacional, focalizando os critérios de movimentação na carreira do magistério presentes nos estatutos e planos de carreira

O método de pesquisa utilizado foi a pesquisa documental com base na coleta e análise dos Planos, com vistas a sistematizar as categorias antes mencionadas. A princípio, houve um levantamento de dados acerca dos trabalhos acadêmicos já realizados sobre a temática em bancos de dados como o Scielo, CAPES, Google Acadêmico e domínio público. As legislações nacionais foram coletadas no site do Portal do Planalto e no Portal do Ministério de Educação. Para ter acesso às legislações sobre a carreira docente dos municípios utilizamos

2 A pesquisa focalizou os estados de Santa Catarina, Rio Grande do Sul, São Paulo, Minas Gerais, Mato Grosso, Mato Grosso do Sul, Paraíba, Paraná, Piauí, Rio Grande Norte, Pará e Roraima e suas capitais. 
a base de dados da pesquisa nacional $l^{3}$ bem como o site das câmaras municipais e dos sindicatos de professores das capitais dos estados selecionados na pesquisa. Utilizamos como embasamento teórico autores que trabalham na área como Araújo (2013), Castro (2006), Dutra Jr et. al (2000), Guimarães (2015), Gurgel e Souza Junior (2013), Torricella (2007), entre outros.

O presente artigo está constituído de duas partes. Na primeira, intitulada "Política de Carreira e Professores da Educação Básica no Brasil: mobilização e regulamentação", realizamos uma breve explanação sobre a legislação e documentos nacionais que normatizam a implantação dos Planos de Cargos e Carreiras no país, procurando estabelecer um diálogo com os autores da área. Em um segundo momento, no tópico intitulado: "Carreira de professores da Educação Básica em capitais brasileiras: estrutura e critérios de movimentação” se discute o marco regulatório que regeu/rege os planos e estatutos dos municípios capitais dos estados investigados, destacando e analisando comparativamente os critérios de movimentação na carreira de professores adotados por cada ente federado. Finalmente, trazemos as conclusões, onde se faz uma síntese das alterações ocorridas nos critérios de movimentação na carreira dos professores dos municípios analisados, considerando-se como parâmetro de análise a instituição do FUNDEB, a partir de 2007, e a criação do PSPN a partir de 2008.

\section{POLÍTICA DE CARREIRA DE PROFESSORES DA EDUCAÇÃO BÁSICA NO BRASIL: MOBILIZAÇÃO E REGULAMENTAÇÃO}

Os primeiros Planos de Cargos e Carreiras ligados ao magistério foram elaborados entre o início dos anos 1970 e 1990, fundamentados pela Lei $n^{\circ}$ 5.692/1971. Segundo Dutra Jr et. al. (2000) os mesmos guardam características comuns quanto à estrutura da carreira e remuneração do magistério público brasileiro em vigência após a Constituição de 1988. Formuladas a partir da década de 1970, as leis estaduais constituíram-se em referência para as legislações municipais, cuja maioria data da década de 1980. Em todas as normas legais estaduais, o regime jurídico adotado é o estatutário, o qual se generalizou como regime jurídico único no nível dos estados, como consequência do texto constitucional de 1988.

Com a crescente taxa de matrículas na Educação Básica pública que aconteceu desde a década de 1950, a escola pública passou a atender um novo tipo de demanda: as camadas populares. Mas a referida expansão das matrículas se

Relatório de Pesquisa Nacional "Remuneração de professores de escolas públicas de Educação Básica” (GUTIERRES; CARVALHO; JACOMINI; BRITO, 2013) 
acentuou durante os anos 1970, quando havia os seguintes quantitativos: Ensino Fundamental, 15.895.000 alunos e 1.119.000 no Ensino Médio; entretanto, uma década após, em 1980, a matrícula ascendia, no Ensino Fundamental, a 22.598.000 de alunos e, no Ensino Médio, a 2.189.000. Esse número de alunos aumentou, em 1991, para 29.204.000 no Ensino Fundamental e 3.770.000 no Ensino Médio; no ano 2000, 35.718.000 de alunos e 8.193.000 no Ensino Médio (CASTRO; LEITE, 2006).

Os professores, que durante as primeiras décadas do século XX eram recrutados das camadas médias para exercer as tarefas de ensino, devido ao crescimento da demanda escolar, começaram a ser recrutados também das camadas populares. No entanto, Dutra Jr et. al. (2000, p. 16) afirmam que "a explosão das matrículas [...] não foi acompanhada por crescimento proporcional de recursos públicos para a educação", culminando assim na consequente desvalorização dos professores, que tiveram que multiplicar jornadas de trabalho, com maior número de alunos, recebendo menores salários.

Conforme Dutra Jr et. al. (2000) dadas às condições deficitárias em relação aos salários e de trabalho, os professores participaram de lutas e greves realizadas nos anos de 1970, juntamente com os demais trabalhadores, em busca de melhorias trabalhistas, mas não conseguiram reverter a desvalorização profissional. Assim, o novo sindicalismo docente desencadeou uma série de mobilizações, lutas sindicais de diversas índoles no contexto do governo militar.

No estado de Rio de Janeiro, por exemplo, em 1979, a Sociedade Estadual dos Professores (SEP) iniciou uma greve em defesa da aposentadoria especial e da elaboração do Estatuto do Magistério e uma segunda greve foi deflagrada nesse mesmo ano pelo Centro Estadual dos Professores (CEP) (ANDRADE, 2001).

Também se registraram greves docentes no estado de Paraná nos anos 1968 e 1978, nas quais participaram professores da capital e região metropolitana em defesa de melhores condições de trabalho e contra os representantes estaduais do governo militar. Mas somente a partir de 1980, houve um envolvimento maciço dos professores do estado numa greve que durou 22 dias; dela participou a maioria dos docentes das cidades, tanto da capital como do interior. Em 1981, o movimento grevista alcançou $80 \%$ dos professores durante 24 dias (RODRIGUES, 2007).

No estado de São Paulo, aconteceram nesse momento histórico duas greves de trabalhadores de grande envergadura: em 1978 e 1979, das quais participaram pela primeira vez os professores, que reivindicavam aumento salarial e a elaboração de um novo Estatuto do Magistério que incorporasse as demandas dos docentes. A greve durou 24 dias, ao final dos quais os docentes saíram vitoriosos, porque se aprovou um novo estatuto e se fortaleceu o movimento 
sindical docente. Entretanto, a greve de 1979, acabou sendo derrotada pelo governo estadual, de Paulo Maluf, que adotou como medida punitiva a exigência aos diretores das escolas que divulgassem as listas dos professores grevistas, com o que se desestimulou a adesão à greve. Os diretores, porém, recusaram essa ordem. Como resultado do enfrentamento político entre os docentes e o governador por conta de que não atendia às reivindicações sindicais, durante os anos 1980, o sindicato realizou várias greves dada a precarização salarial e o baixo poder aquisitivo dos docentes. (CAÇÃO, 2001).

De acordo com Guimarães (2015, p. 60) “a efetivação de políticas públicas que valorizassem a ação docente, em aspectos como remuneração, carreira, formação e condições de trabalho" esteve muito presente nas manifestações de luta e reivindicações dos professores em todo o Brasil. As mobilizações exprimiam a situação precária do trabalho docente no país.

No final da década de 1980, esse contexto de tensão política mudou, como consequência do emergente Estado Democrático de Direito garantido pela Constituição da República Federativa do Brasil (1988), que incorporou no texto uma reivindicação histórica do movimento docente: o entendimento de que a valorização profissional do magistério é condição fundamental para a garantia de um padrão de qualidade da educação. A partir de então, a valorização do magistério em âmbito nacional esteve presente nos debates e na elaboração das reformas educacionais que se acunharam nos anos 1990 e 2000.

No entanto, as reformas educacionais brasileiras estão intrinsecamente ligadas a movimentos de organismos internacionais que prezam pela reorganização do capital e reestruturação do trabalho, pois segundo Guimarães (2015),

A carreira e remuneração dos profissionais do magistério público brasileiro insere-se em um cenário amplo no qual são definidas as políticas educacionais, protagonizado por atores internos e externos ao Estado-Nação e que mantém íntima relação com as transformações do modo de produção capitalista em nível global. (p. 34).

As exigências das instituições financeiras internacionais presentes em documentos oficiais tiveram influência na implantação das políticas educacionais no Brasil, fazendo assim sobressair novas configurações que reforçam a subordinação da educação e, consequentemente do trabalhador docente, aos princípios econômicos do capital.

Destacamos que grande parte das reformas educacionais foi implementada tendo como base as mudanças na legislação e que tanto seu formato final como sua aplicabilidade são resultados de embates teóricos e políticos travados entre as partes interessadas, ou seja, a elaboração e implementação das políticas públicas 
são definidas em contextos nos quais, em determinados momentos, sobrepõem-se os interesses da classe trabalhadora, em outros, tais interesses são secundarizados em detrimento das forças políticas dadas no momento.

De forma a contextualizar brevemente acerca das normas que regulam os Planos de Cargos e Carreiras da Educação Básica, analisaremos, a seguir, os marcos nacionais que trouxeram, em forma de lei, garantias de direitos aos trabalhadores da educação. Após extenso processo de elaboração e votação, a Constituição Federal foi promulgada em outubro de 1988, cercada por grandes expectativas. Após vinte anos de ditadura e violação de direitos, as organizações populares, representantes da classe trabalhadora e da burguesia travaram um grande embate com relação aos princípios e direitos que a Carta Magna deveria assegurar. Isto resulta em que a redação final da CF se mostra ambígua pelo fato de:

Reforçar a ordem burguesa, na medida em que constitucionaliza o direito de propriedade, a livre iniciativa, a herança, a livre concorrência - institutos basilares do regime capitalista; e por outro, ao ordenar a essa burguesia que garanta a existência de uma sociedade livre, justa e solidária, capaz de garantir a soberania nacional, erradicar a pobreza e reduzir as desigualdades sociais e regionais. Trata-se, pois, de uma carta social-democrata com tonalidades nacionalistas. (CARDOSO JUNIOR, 2009. p. 40)

Com efeito, como resultado de um longo período ditatorial de violações de direitos, aconteceu o processo de redemocratização do país, no qual as organizações populares, inclusive dos professores, lutaram ativamente no processo de elaboração da constituinte e sua participação foi de extrema importância para garantir, em forma de lei, direitos básicos como educação pública de qualidade às camadas populares.

$\mathrm{Na}$ Constituição Federal (1988), no Capítulo que trata da Educação Nacional, estabelecem-se como fundamentos básicos: a qualidade do ensino, a gestão democrática e o acesso gratuito, considerados como princípios basilares da nação. Com relação ao magistério, no artigo 206, inciso V, verifica-se:

Valorização dos profissionais da educação escolar, garantidos, na forma da lei, planos de carreira, com ingresso exclusivamente por concurso público de provas e títulos, aos das redes públicas (BRASIL, 1988, s/p).

Tal garantia foi inclusa pela Emenda Constitucional no 53 de 2006, a mesma que inseriu no artigo antes citado, o inciso VIII, que fixa o piso salarial profissional nacional para os profissionais da educação escolar pública nos termos de Lei Federal. 
Outro documento considerado fundamental para compreender o processo histórico de institucionalização dos planos e cargos de carreira do magistério é a Lei de Diretrizes e Bases da Educação, Lei 93.94/1996, (BRASIL. 1996) que define e regulamenta o sistema de educação no Brasil com base nos princípios presentes na Constituição. Ressalta-se que esta norma foi instituída durante os anos 1990, num contexto de reformas educativas, mais precisamente no primeiro mandato do presidente Fernando Henrique Cardoso (1995-2003).

Essas reformas abarcavam todos os níveis do ensino e visavam a atender às recomendações internacionais advindas de organismos bilaterais de financiamento como o Banco Mundial, Banco Interamericano de Desenvolvimento e, mais especificamente, da Organização das Nações Unidas para a Educação, a Ciência e a Cultura (UNESCO), que salientavam a necessidade de reformular os conteúdos curriculares, a gestão, o financiamento educativo e também as questões relacionadas com a formação, a avaliação e a regulamentação do trabalho dos professores.

Sendo assim, a elaboração do projeto da LDB, que vinha de um processo de longa discussão e participação social, centrado em princípios democráticos que atenderam às demandas da sociedade civil, no início dos anos 1990, enfrentará um contexto político e econômico caracterizado pela reestruturação produtiva e por diretrizes ideológicas de caráter neoliberal, situação que vai impactar na redação final, porque foram incorporadas algumas das orientações dos referidos organismos internacionais.

Segundo afirma Pino (1992), é possível verificar dois momentos no processo de tramitação da LDB, Lei 93.94/1996; o primeiro se iniciou com a elaboração do anteprojeto em 1987, quando houve a participação da sociedade civil e acadêmica na defesa da escola pública, gratuita e universal, principalmente mediante os Fóruns Nacional e os Estaduais, as forças políticas, sindicais e de diversas organizações envolvidos na elaboração da proposta estavam a favor dos interesses democráticos e das necessidades das classes trabalhadoras. Em um segundo momento, a tramitação do projeto de lei foi marcado pelo jogo de interesses que estavam presentes no Congresso Nacional, sobretudo dos representantes das escolas privadas e confessionais.

Conforme Conceição (2009), as contribuições dos educadores para o debate, por se contraporem à ideologia e às políticas de ajuste, foram desconsideradas na elaboração do documento. Consideramos, então, que a Lei 9.394/1996, Lei de Diretrizes e Bases da Educação Básica Nacional, que regulamentou a Constituição Federal (1988), foi produto de uma movimentação 
política que ignorou as organizações populares, que prezavam por uma educação gratuita, laica, de qualidade, e legitimou a maior parte dos interesses de facções da classe dominante.

Em relação à valorização dos professores a Lei de Diretrizes e Bases da Educação Nacional (LDB), Lei nº 9.394/1996, apresenta no Artigo 67 o seguinte:

Art. 67. Os sistemas de ensino promoverão a valorização dos profissionais da educação, assegurando-lhes, inclusive nos termos dos estatutos e dos planos de carreira do magistério público:

I - ingresso exclusivamente por concurso público de provas e títulos;

II - aperfeiçoamento profissional continuado, inclusive com licenciamento periódico remunerado para esse fim;

III - piso salarial profissional;

IV - progressão funcional baseada na titulação ou habilitação e, na avaliação de desempenho;

$\mathrm{V}$ - período reservado a estudos, planejamento e avaliação, incluído na carga de trabalho;

VI - condições adequadas de trabalho (BRASIL, 1996, s/p, grifos nossos).

Segundo a citada lei, está estabelecido que os Planos de Carreira e os Estatutos do magistério público devem garantir o ingresso exclusivamente por meio de concursos públicos, possibilitar o aperfeiçoamento com licença remunerada, assegurar piso salarial, progressão funcional, condições de trabalho, entre outras coisas, afirmando-se assim, por lei, direitos importantes para a classe.

Em 1996, foi aprovada a Emenda Constitucional 14/1996 que criou o FUNDEF, que subvinculou $15 \%$ dos impostos dos estados e municípios ao Ensino Fundamental, por um período de dez anos. O FUNDEF centralizava recursos, a princípio, para depois redistribuí-los de acordo com o número de matrículas existentes nas redes de ensino. Sendo assim, assumiu uma natureza de fundo de gestão, não gerando novos recursos, só canalizando os já previstos (GEMAQUE, 2007).

De certa maneira, o FUNDEF, ao focar apenas o financiamento do Ensino Fundamental, seguiu um caminho de contenção de recursos depositados na área educacional e abandonou a alternativa pelo direito universal a educação de qualidade. A estratégia redistributiva que, apesar de esboçar uma hipotética equidade, primava por ampliar uma suposta eficácia da atuação governamental, focalizando em uma etapa especifica da Educação Básica em detrimentos de das outras.

Em 2005, com o período de vigência do FUNDEF chegando ao fim, o debate sobre a próxima elaboração de estratégias para o financiamento da educação foi tenso. Embora houvesse diversas Propostas de Emenda Constitucional (PECs) acerca do tema, o debate centrou-se na PEC 415/2005, apresentada pelo 
governo, que culminou com a Emenda Constitucional no 53/2006 que criou o Fundo de Manutenção e Desenvolvimento da Educação Básica e de Valorização dos Profissionais da Educação (FUNDEB), regulamentado em julho de 2007 pela Lei n ${ }^{\circ}$ 11.494/2007. Esse Fundo amplia o foco do FUNDEF, englobando toda a Educação Básica (Ensino Fundamental, Educação Infantil e Ensino Médio) por um período de 14 anos; previu a valorização dos profissionais da educação por meio de planos de carreira; aumentou os percentuais de vinculação dos recursos que compunham o FUNDEF de 15\% para 20\%; e subvinculou outros impostos que compõem a estrutura de financiamento educacional brasileiro.

A implantação do FUNDEB aconteceu gradualmente nos três primeiros anos de sua vigência - 2007 a 2009 - e deve perdurar até dezembro de 2020. De acordo com Freire (2015), o FUNDEB surgiu pela necessidade causada pelo FUNDEF, que logo iria findar-se, em 2006, que causou um descompasso entre as etapas da Educação Básica, prejudicou a universalização e a melhoria da qualidade da educação pública, assim como também, "Pela multiplicação de desvios de verbas, ineficácia dos Conselhos, lentidão na melhoria salarial dos professores, descumprimento do valor mínimo e demanda pelo ensino médio sem cobertura financeira" (FREIRE, 2015, p. 147).

O FUNDEB manteve semelhanças com o FUNDEF, o que permite alguns autores, como Araújo (2013), caracterizá-lo como legado em continuidade com o antigo Fundo. Dentre as similaridades, destacamos a manutenção dos fundos por estados, a previsão de no mínimo $60 \%$ desses recursos para a remuneração do magistério, a obrigação da implantação dos Planos de Carreira e o caráter distributivo proporcional ao número de alunos matriculados.

Em conformidade com a legislação vigente, o Conselho Nacional de Educação (CNE) aprovou, em 2009, a Resolução no 02/2009 (BRASIL, 2009) que fixa as Diretrizes para os Planos de Carreira e Remuneração dos Profissionais do Magistério da Educação Básica Pública. De acordo com Guimarães (2015, p. 60) essa “[...] resolução determinou como obrigatoriedade a instituição de Planos de Cargos, Carreira e Remuneração aos profissionais do magistério, cabendo aos entes federados a avaliação sobre a construção de planos padronizados que considerassem os demais profissionais da educação".

$\mathrm{O}$ artigo $4^{\circ}$ dessa Resolução, ao tratar dos princípios para a instituição do plano de carreira, reporta-se à progressão na carreira prevista por meio de incentivos que perpassam a titulação, experiência, desempenho, atualização e aperfeiçoamento, conforme a redação: 
Art. $4^{\circ}[\ldots]$ V- Progressão salarial na carreira, por incentivos que contemplem titulação, experiência, desempenho, atualização e aperfeiçoamento profissional; $[\ldots]$

XII- estabelecimento de critérios objetivos para a movimentação dos profissionais entre unidades escolares, tendo como base os interesses da aprendizagem dos educandos (BRASIL, 2009, grifos nossos).

No que diz respeito à questão da movimentação na carreira por avaliação de desempenho, o artigo $5^{\circ}$ da referida resolução destaca que os incentivos a esse tipo de progressão serão mediante avaliação de desempenho do profissional do magistério (Idem).

Entre outras determinações, as Diretrizes Nacionais fixam que o salário inicial para as carreiras dos profissionais da educação respeitando a respectiva jornada de trabalho estabelecida nos planos de cargos, em relação a valores, nunca deve ser inferior ao do Piso Salarial Profissional Nacional. Estabelecem também a diferenciação dos salários iniciais por titulação básica entre os habilitados em nível médio e os habilitados em nível superior e pós-graduação lato sensu além de assegurar a revisão salarial anual dos salários iniciais e das remunerações de carreira para preservar o poder aquisitivo dos educadores. Sendo assim, as diretrizes determinam nacionalmente importantes garantias à classe dos trabalhadores em educação em relação à remuneração docente.

Um aspecto a ser destacado durante o segundo mandato do governo de Luiz Inácio Lula da Silva (2003-2010) é o esforço por induzir a materialização de forma maciça de elaboração de Planos de Cargos, Carreira e Remunerações dos professores da Educação Básica, dado que ainda havia no país um número considerável de municípios que não contavam com o documento que regulamenta a atividade profissional dos docentes. O Decreto $n^{\circ}$ 6.094, de 24 de abril de $2007^{4}$ que dispõe sobre o Plano de Metas Compromisso Todos pela Educação, base de implementação do Plano de Ações Articuladas (PAR), também menciona a avaliação do desempenho do professor nos Planos de carreira.

Assim, entre as medidas que foram adotadas nesse momento histórico, ressalta-se também a Lei n ${ }^{\circ} 11.738$ instituindo o piso salarial profissional nacional para os profissionais do magistério público da Educação Básica, que contribuiu para incentivar a equiparação salarial dos professores em todo país, apesar das inúmeras resistências para sua implementação.

4 Dispõe sobre a implementação do Plano de Metas Compromisso Todos pela Educação, pela União Federal, em regime de colaboração com Municípios, Distrito Federal e Estados, e a participação das famílias e da comunidade, mediante programas e ações de assistência técnica e financeira, visando à mobilização social pela melhoria da qualidade da educação básica. 
A cartilha "Planos de Carreira e Remuneração: contribuições para a elaboração e a revisão de planos de carreira e remuneração dos profissionais da educação escolar básica pública", publicada em 2016, elaborada pelo Ministério da Educação com base nas legislações historicamente estabelecidas, apresenta orientações para a elaboração de Planos de Cargos e Carreiras com objetivo de oferecer apoio técnico para os dirigentes e suas equipes, possibilita uma avaliação sobre os impactos financeiros decorrentes das diferentes formas de organização de um plano de carreira e remuneração para os profissionais do magistério, expondo também sugestões de elaboração do mesmo, explana que "a remuneração dos profissionais da educação é considerada prioridade para a educação nacional" (BRASIL, 2016, p. 10)

A remuneração, a carreira e as condições de trabalho do magistério estão ligados, historicamente, à qualidade do ensino público e ao desenvolvimento do processo de (des)valorização docente. De acordo com Rocha (2009) no decorrer da construção e organização da educação brasileira, a valorização docente citada estabeleceu-se em um jogo conflitante de valores "que são próprios do processo educacional [...] e o não reconhecimento desses valores pelos poderes públicos em suas políticas de formação profissional, salários e incentivos." (ROCHA, 2009, p. 21)

É nesse contexto histórico de mudanças nas orientações legais sobre a valorização docente que situamos a necessidade de aprofundar estudos sobre as possíveis mudanças nos critérios de movimentação na carreira de docentes no Brasil. Nesse sentido, na seção a seguir conheceremos as informações referentes à carreira de professores nos municípios de Florianópolis, Porto Alegre, São Paulo, Belo Horizonte, Cuiabá, Curitiba, Campo Grande, João Pessoa, Teresina, Natal, Belém e Boa Vista.

\section{CARREIRA DE PROFESSORES DA EDUCAÇÃO BÁSICA EM CAPITAIS BRASILEIRAS: ESTRUTURA E CRITÉRIOS DE MOVIMENTAÇÃO}

A carreira dos profissionais de educação dos municípios analisados segue uma estrutura e movimentação previstas nos planos e estatutos. Nesse contexto, com base no marco regulatório e dados disponibilizados no relatório da pesquisa nacional, que definem a estrutura e movimentação, será realizada uma análise comparativa desses aspectos nos municípios selecionados. 


\section{a) Estrutura da Carreira docente nos municípios}

A configuração da carreira docente nos municípios pesquisados apresenta as mais diferentes formas. Há grande variedade no número de cargos, de classes/ padrão/níveis/referências, conforme a formação e os graus de movimentação na carreira. O interstício de tempo necessário para que haja progressão na carreira também é variado, o que impacta na amplitude de tempo de duração da carreira (desde o ingresso até a aposentadoria).

A esse respeito, os dados constantes no quadro a seguir apresentam as seguintes informações:

\section{Quadro 01 - Estrutura da Carreira Docente em Municípios Brasileiros}

\begin{tabular}{|c|c|c|c|c|c|c|}
\hline Local & Cargo & $\begin{array}{c}\text { Classe/ } \\
\text { Padrão/Nível/ } \\
\text { Referência }\end{array}$ & Formação & $\begin{array}{c}\text { Classe, Nível, } \\
\text { Referência ou } \\
\text { Grau }\end{array}$ & Interstíc. & $\begin{array}{l}\text { Amplitude da } \\
\text { Carreira } \\
\text { (anos) })^{*}\end{array}$ \\
\hline BEL & - & $3(1,2,4)$ & Méd. a Plena. & 13 (1 a 13) & 2 & 29 \\
\hline BH & 2 & 2 & Méd. e Plena. & $\begin{array}{c}12(1 \text { a } 12) \\
14(10 \text { a } 24)\end{array}$ & variável & 31 \\
\hline BV & - & $5(\mathrm{I}$ a V $)$ & Méd. a Dout. & 15 (N1-N15) & 2 & 33 \\
\hline CG & - & $5(1$ a 5$)$ & Méd. a Dout. & $8(\mathrm{~A}$ a H $)$ & 3 a 6 & 27 \\
\hline CB & - & 3 (I a III) & Plen. a M/Dou. & $7(A-G)$ & 5 & 38 \\
\hline CURT & 2 & 4 (I a VI) & Plena a Dout. & $9(A-I)$ & 2 & 21 \\
\hline FLOR & 2 & 4 (III a VI) & Plena a Dout. & $9(A-I)$ & 2 a 3 & 21 a 30 \\
\hline JP & 2 & $\begin{array}{l}5(\mathrm{~A} a \mathrm{E}) \\
4(\mathrm{~A} a \mathrm{D})\end{array}$ & $\begin{array}{l}\text { Méd. a Dout. } \\
\text { Plena a Dout. }\end{array}$ & $5(I-V)$ & 5 & 28 \\
\hline NT & 2 & $\begin{array}{c}2(1,2) \\
3(A, B, C)\end{array}$ & $\begin{array}{l}\text { Plena a Pós } \\
\text { Méd. a Pós }\end{array}$ & $\begin{array}{c}15(\mathrm{~A}-\mathrm{P}) \\
15(\mathrm{I} \text { a XV) }\end{array}$ & $\begin{array}{l}4 \\
2\end{array}$ & 33 \\
\hline POA & - & $5(1-5)$ & Méd. a Dout. & $4(A-D)$ & 6 & 27 \\
\hline SP & 3 & $10(11-21)$ & Méd. a Plena. & $5(A-E)$ & variável & 22 \\
\hline TE & 2 & $3(C, B, A)$ & Lic. Plena & 13 (V a I) & variável & 33 \\
\hline
\end{tabular}

Fonte: Gutierres; Carvalho; Jacomini; Brito, 2013.

Nota: * Está incluído o tempo relativo ao estágio probatório de 3 anos.

Existe mais de um cargo de professor em alguns municípios, a exemplo de Belo Horizonte (2), Curitiba (2), São Paulo (3), Florianópolis (2), Natal (2) e Teresina (2). A passagem de um para outro cargo se faz mediante concurso ou formação acadêmica, a critério de cada sistema. De maneira geral, o cargo de professor comporta escalonamentos de acordo com a formação acadêmica, que recebem diferentes nomenclaturas como: categoria funcional (Belém), níveis (Campo Grande, Cuiabá, Curitiba, Florianópolis, Natal - para o Ens. Fundamental, Porto Alegre), classes (Belo Horizonte, Boa Vista, Teresina) ou 
Padrão (Natal -para Ed. infantil). As formações consideradas dos professores nos municípios variam de Ensino Médio a Doutorado (Boa Vista, Campo Grande, João Pessoa, Porto Alegre, Natal); médio a superior (Belém, Belo Horizonte, São Paulo); superior a mestrado/Doutorado (Curitiba, Florianópolis, Cuiabá) e, sem variação de escalonamento, o município de Teresina, que considera apenas a formação superior (Licenciatura Plena) como pré-requisito para a entrada tanto dos professores de primeiro ciclo quanto para os de segundo ciclo.

As carreiras docentes de todos os municípios também apresentam escalonamentos conforme o tempo de serviço, a formação em serviço e a avaliação de desempenho, chamados de referências (Belém, Curitiba, João Pessoa, São Paulo e Porto Alegre); níveis (Belo Horizonte, Boa Vista, Natal Infantil e Teresina) e classes (Campo Grande, Curitiba, Florianópolis e Natal Fundamental). O município de São Paulo, além do uso do termo "referências" para evolução na carreira, utiliza também a denominação de "graus".

A estrutura de carreira do magistério nos municípios abrange as mais diversas formas, variando na quantidade de cargos e na amplitude da carreira. A grande maioria (91,7\%) dos planos pesquisados estrutura os cargos de acordo com o nível de formação e não segundo a área de atuação do professor, conforme recomenda a Resolução n ${ }^{\circ}$ 02/2009 que define Diretrizes nacionais para carreira docente da Educação Básica. A exceção é o município de Natal, que apresenta Plano de Carreira para os professores de Educação Infantil em separado.

A amplitude da carreira leva em conta a duração da carreira, considerando o menor e o maior escalonamento da carreira em um mesmo cargo e é muito variada e difícil de precisar, pois, em boa parte dos estatutos e planos de carreira, o interstício de tempo de progressão/evolução na carreira depende do desempenho docente e em alguns casos, de orçamento, o que tende a flexibilizar o tempo de sua duração. Por conseguinte, os tempos aqui apresentados para as carreiras a título de amplitude da carreira são meramente aproximações.

\section{b) Movimentação na carreira baseada na formação e titulação acadêmica}

A progressão/evolução na carreira docente baseada na formação e titulação acadêmica nos municípios analisados associa-se a outras regras como tempo de serviço e avaliação de desempenho. A progressão/evolução na carreira recebe as mais diferentes denominações nos municípios: progressão funcional vertical (Belém); promoção por titulação ou progressão vertical (Boa Vista); progressão funcional (Natal); progressão vertical (João Pessoa); promoção vertical (Campo Grande); promoção de nível (Cuiabá); evolução funcional por título (São Paulo); progressão profissional (Belo Horizonte); progresso funcional por 
acesso (Florianópolis); ascensão (Porto Alegre); crescimento vertical (Curitiba). Em 41,6\% dos municípios este tipo de movimentação recebe o qualificativo "vertical". Nos municípios de Teresina, Florianópolis e Curitiba a promoção requer também aferição de conhecimento e depende de previsão orçamentária. Em Belo Horizonte a titulação não altera o cargo, apenas contribui para o crescimento horizontal. O quadro a seguir apresenta de forma resumida, outros critérios estabelecidos para a realização da movimentação vertical nos planos de carreira dos municípios, para além da titulação:

\section{Quadro 2 - Critérios para movimentação vertical na carreira docente nos Municípios}

\begin{tabular}{|c|c|}
\hline Critérios para movimentação vertical & Municípios \\
\hline Titulação e aperfeiçoamento & Florianópolis \\
\hline Titulação e Avaliação de desempenho & Boa Vista, Cuiabá \\
\hline Previsão orçamentária e Avaliação & Curitiba, Teresina \\
\hline
\end{tabular}

Fonte: Gutierres; Carvalho; Jacomini; Brito, 2013.

A progressão vertical nos municípios está relacionada à formação (obtenção de nova titulação) e, em alguns deles, além da formação se interpõem o tempo, a previsão orçamentária e a avaliação de desempenho. Na grande maioria dos municípios analisados, ela é concedida mediante a apresentação de uma nova titulação. Em Teresina e Curitiba, a progressão vertical está condicionada à previsão orçamentária. Em Boa Vista e Cuiabá, além da titulação exige-se a avaliação de desempenho. O processo seletivo é condição para a progressão funcional vertical em Curitiba. Em Belém, apesar de a lei prever a progressão vertical automática, isso não ocorre.

\section{c) Movimentação na carreira baseada na formação continuada, na avaliação de desempenho e no tempo de serviço}

A movimentação na carreira baseada na formação continuada, na avaliação de desempenho e no tempo de serviço nos municípios analisados recebe diferentes denominações e pode estar relacionada a outras regras como disponibilidade orçamentária e testes de conhecimentos. A movimentação na carreira nos municípios recebe diversos nomes: promoção horizontal (Campo Grande); progressão de classe (Cuiabá); progressão funcional horizontal (Belém; Boa Vista); promoção (Natal - Ens. Fundamental; Florianópolis); progressão (Teresina; Natal - infantil;) promoção (São Paulo); progressão profissional (Belo 
Horizonte); progressão horizontal (Porto Alegre; João Pessoa); crescimento horizontal (Curitiba). Em 50\% dos municípios assim como nos Estados, adotase o qualificativo horizontal, razão porque, também será o termo adotado neste trabalho. Vejamos a incidência dos critérios formação continuada, avaliação de desempenho e tempo de serviço para esse tipo de movimentação na carreira e as condicionalidades adotadas para a promoção horizontal nos municípios da pesquisa. O quadro que segue sintetiza os critérios apresentados nos planos de carreira para a realização da movimentação horizontal:

\section{Quadro 3 - Critérios para movimentação horizontal na Carreira nos Municípios}

\begin{tabular}{|c|c|c|}
\hline Critérios & Municípios & $\%$ \\
\hline Tempo & Todos (com variação de interstícios) & $100 \%$ \\
\hline Avaliação de desempenho & Bel; BH; BV; CB, CG, NT, SP, TE, JP & $75 \%$ \\
\hline Merecimento & CG; TE; SP; POA & $33,3 \%$ \\
\hline Formação continuada & Curt, Nt, JP, TE & $33,3 \%$ \\
\hline Assiduidade, aperfeiçoamento & Flor. & $8,3 \%$ \\
\hline Previsão orçamentária & TE; Curt & $16,6 \%$ \\
\hline Existência de vagas & POA; SP & $16,6 \%$ \\
\hline Avaliação de Conhecimentos & JP; TE & $16,6 \%$ \\
\hline
\end{tabular}

Fonte: Gutierres; Carvalho; Jacomini; Brito, 2013.

A movimentação na carreira no seu sentido horizontal em todos os municípios da pesquisa leva em conta o interstício mínimo de 2 anos ao máximo de 6 anos. Em 41,7\% dos municípios a progressão por tempo ocorre a cada 2 anos; em 33,3\% deles ocorre a cada 3 anos; em 25\% a cada 5 anos e 6 anos.

Independentemente das nomenclaturas utilizadas, o tempo de serviço aparece em 100\% dos planos como pré-requisito para progressão horizontal. A avaliação de desempenho se repete como pré-requisito para progressão horizontal em 75\% dos planos dos municípios alisados. Em 33,3\% (4) dos planos, além do tempo, o merecimento constitui pré-requisito, assim como a formação continuada, que apresenta o mesmo percentual de 33\%. Em Florianópolis, aparece a combinação dos critérios: tempo, assiduidade e aperfeiçoamento. As avaliações de desempenho envolvem: avaliação de conhecimentos, pontuações, frequência a cursos, cumprimento de metas de aprovação, assiduidade, disciplina, publicação de artigos, entre outros requisitos. 
Segundo o Plano de Carreira dos professores de Boa Vista, a avaliação de desempenho é precedida da composição de subcomissão temporária de avaliação na unidade escolar, composta pelo diretor, um professor e o próprio servidor que está sendo avaliado. A participação dos envolvidos com a causa educacional em processos avaliativos é endossada por experiências internacionais que, segundo Torricella (2007), recomendam o seguinte:

\footnotetext{
As experiências internacionais endossam as seguintes recomendações: um sistema de avaliação de desempenho deve ser construído com a participação de professores, sindicatos e comunidade educacional; deve atender princípios de equidade, transparência e justiça para ter credibilidade; é necessário criar uma imagem construtiva da avaliação a favor do professor e de sua atuação profissional; a avaliação docente deve articular-se com a avaliação da escola; a avaliação deve concorrer para a melhoria da qualidade da docência. (TORRICELLA, 2007, p. 24).
}

As administrações municipais também apresentam alguns fatores que condicionam a implementação dos direitos previstos nos planos e estatutos que impedem a movimentação na carreira, seja no sentido horizontal ou vertical, como, por exemplo, a falta de previsão orçamentária para destinar recursos suficientes que permitam a progressão funcional dos docentes, bem como a existência e número de vagas necessárias destinadas aos cargos docentes, implicações essas que retardam a valorização dos profissionais de educação.

\section{CONSIDERAÇÕES FINAIS}

Grande parte das reformas educacionais da década de 1990 foram implantadas com base nas legislações, cuja elaboração, resultado final e aplicabilidade foram resultantes de embates teóricos e políticos travados entre os que representavam os interesses das classes trabalhadoras e os expoentes das classes dominantes. Sendo assim, vários documentos que normatizam os Planos de Cargos e Carreiras como a CF/88, a Lei 9.394/1996 (LDB), a Emenda Constitucional no 53 , e as Diretrizes dos Planos de Cargos e Carreiras (Resolução $\left.\mathrm{n}^{\circ} 02 / 2009\right)$ trazem as marcas dessas contradições.

A Constituição Federal (1988) determina como direito social o acesso a uma educação pública e de qualidade e solidificou o entendimento de que a valorização profissional do magistério é condição fundamental para a garantia de tal direito. E um dos meios para a concretização da valorização do professor é a implementação de Planos de carreira que contemplem possibilidades de movimentação na carreira. 
As legislações que regulamentam o financiamento da educação, o FUNDEF e o FUNDEB instituem a obrigatoriedade da implantação dos planos de carreira em todos os entes da federação. Posteriormente, a lei do PSPN reafirma a necessidade da materialização dos planos com o objetivo de garantir a valorização dos profissionais de educação.

Nesse sentido, as normas legais são instrumentos necessários para que os professores negociem com os governos locais melhores condições de remuneração, subsidiados pela legislação nacional e local. Entretanto, a pesquisa permitiu verificar que, apesar das garantias presentes nas normas legais, não há como garantir a efetivação dos planos de carreira.

No caso dos 12 municípios pesquisados, verificou-se que há grande variedade no formato das carreiras, que apresentam desenho muito particular, com critérios diferenciados de movimentação na carreira dos professores em cada capital. Para a movimentação vertical, além da titulação há tendência de se exigir avaliação de desempenho e de conhecimentos; para a progressão horizontal, além do tempo de serviço, a avaliação de desempenho, o merecimento e a formação continuada fazem parte das exigências. Em ambos os casos, alguns municípios condicionam a movimentação na carreira a limites orçamentários, o que pode limitar a progressão funcional do professor mesmo que ele cumpra todos os prérequisitos.

Constatou-se nas legislações analisadas normatizações para a garantia da valorização dos profissionais de educação escolar, como ingresso dos docentes na rede pública de ensino exclusivamente por concurso público de provas e títulos. Por conseguinte, a obrigatoriedade de Plano de Cargos e Carreira precisa materializar-se para a consolidação desses direitos dos profissionais de educação no Brasil.

Contudo, os planos de carreira são importantes tanto para a valorização dos profissionais de educação como para a qualidade da educação. A progressão na carreira depende dos recursos públicos que são destinados à educação, bem como o compromisso dos governantes para o cumprimento das normas legais que regulam a carreira dos profissionais de educação. 


\section{REFERÊNCIAS}

ANDRADE, Teresa Ventura de. A União dos Professores do Rio de Janeiro: Um capítulo da história da organização docente (1948-1979). Niterói: Universidade Federal Fulminense, 2001.

ARAÚJO, Raimundo Luiz Silva. Limites e possibilidades da redução das desigualdades territoriais por meio do financiamento da educação básica. 2013. 401 p. Tese (Doutorado em Educação) - Universidade de São Paulo, São Paulo, 2013.

BRASIL. Ministério da Educação. Secretaria de Articulação com os Sistemas de Ensino Planos de carreira e remuneração: contribuições para a elaboração e a revisão de planos de carreira e remuneração dos profissionais da educação escolar básica pública / Organizado por Sérgio Roberto Gomes de Souza. -- Brasília: MEC/SASE, 2016. 88 p.

BRASIL. MINISTÉRIO DA EDUCAÇÃO (MEC). Conselho Nacional de Educação (CNE). Câmara de Educação Básica (CEB). Resolução no 2, de 28 de maio de 2009. Fixa as Diretrizes Nacionais para os Planos de Carreira e Remuneração dos Profissionais do Magistério da Educação Básica Pública. Diário Oficial da União, Brasília (DF): MEC, CNE/CEB, 1997.

BRASIL. Lei $\mathbf{n}^{\mathbf{0}}$ 11.494, de 20 de junho de 2007. Regulamenta o Fundo de Manutenção e Desenvolvimento da Educação Básica e de Valorização dos Profissionais da Educação - FUNDEB, de que trata o art. 60 do Ato das Disposições Constitucionais Transitórias; altera a Lei no 10.195, de 14 de fevereiro de 2001; revoga dispositivos das Leis nos 9.424, de 24 de dezembro de 1996, 10.880, de 9 de junho de 2004, e 10.845, de 5 de março de 2004; e dá outras providências. Disponível em: <http://www.planalto.gov.br/ccivil_03/_ato20072010/2007/lei/111494.htm>. Acesso em: 17 fev. 2018.

BRASIL. Emenda constitucional $\mathbf{n}^{\circ}$ 53, de 19 de dezembro de 2006. Dá nova redação aos arts. $7^{\circ}, 23,30,206,208,211$ e 212 da Constituição Federal e ao art. 60 do Ato das Disposições Constitucionais Transitórias. Disponível em: <http:/ / www.planalto.gov.br/ccivil_03/Constituicao/Emendas/Emc/emc53.htm>. Acesso em: 17 fev. 2018, 
BRASIL. Lei $\mathrm{n}^{\circ} \mathbf{9 . 4 2 4}$, de 24 de dezembro de 1996. Dispõe sobre o Fundo de Manutenção e Desenvolvimento do Ensino Fundamental e de Valorização do Magistério, na forma prevista no art. $60, \int 7^{\circ}$, do Ato das Disposições Constitucionais Transitórias, e dá outras providências. <http://www.planalto.gov. br/Ccivil_03/leis/L9424.htm>. Acesso em: 17 fev. 2018.

BRASIL. Lei $\mathbf{n}^{\circ} \mathbf{9 . 3 9 4}$, de 20 de dezembro de 1996. Estabelece as diretrizes e bases da educação nacional. <http://www.planalto.gov.br/Ccivil_03/leis/L9394. htm>. Acesso em: 17 fev. 2018.

BRASIL. Constituição da República Federativa do Brasil. Brasília, DF, 5 out.1988. Disponível em: <http://www.planalto.gov.br/ccivil_03/constituicao/ constituicaocompilado.htm>. Acesso em 10 set. 2017.

BRASIL. Lei n ${ }^{\circ}$ 11.738, de 16 de julho de 2008. Regulamenta a alínea "e" do inciso III do caput do art. 60 do Ato das Disposições Constitucionais Transitórias, para instituir o piso salarial profissional nacional para os profissionais do magistério público da educação básica. Disponível em: <http://www.planalto.gov.br/ ccivil_03/_ato2007-2010/2008/lei/111738.htm>. Acesso em: 17 fev. 2018.

BRASIL. Ministério da Educação - MEC. Planos de Carreira e Remuneração: contribuições para a elaboração e a revisão de planos de carreira e remuneração dos profissionais da educação escolar básica pública. Brasilia. 2016. Disponível em: $\quad<$ http://unesdoc.unesco.org/images/0024/002448/244818POR.pdf>. Acesso em 17 fev. 2018.

CAÇÃO, Maria Izaura. Jornada de trabalho docente: delineamento histórico da organização do trabalho do magistério público estadual paulista. 2001. 218 p. Tese (Doutorado em Educação) - Universidade Estadual de Campinas, Campinas, 2001.

CARDOSO JUNIOR, José Celso. A constituição brasileira de 1988 revisitada: recuperação histórica e desafios atuais das políticas públicas nas áreas econômica e social. Brasília: Ipea, 2009, p. 291.

CASTRO, Maria Helena de Magalhães; LEITE, Elenice Monteiro. Educação no Brasil: atrasos, conquistas e desafios. In: TAFNER Paulo (editor) Brasil: o estado de uma nação - mercado de trabalho, emprego e informalidade. Rio de Janeiro: IPEA, 2006, p. 119-228. 
CONCEIÇÃO, Lucy Mara. A construção do projeto político pedagógico do município de Londrina - resgatando uma história. 2009. 89 p. Dissertação (Mestrado em Educação) - Universidade Estadual de Londrina, Londrina, 2009.

DUTRA JÚNIOR et al. Plano de carreira e remuneração do magistério público: LDB, FUNDEF, Diretrizes nacionais e nova concepção de carreira. Brasília: FUNDESCOLA/MEC, 2000.

FREIRE, Eduardo José. FUNDEB: solução para os males da educação? Revista Produção on - line. REFAF - Faculdade de Alta Floresta. Mato Grosso. v. 2, n. 4, p. 144-15, 2015. Disponível em: < http://www.refaf.com.br/index.php/ refaf>. Acesso em: 02 mar. 2018.

GEMAQUE, Rosana Maria Oliveira Rolim. A proposta de criação do FUNDEB e sua relação com os estudos sobre os impactos do FUNDEF na educação do Estado do Pará. Jornal de políticas públicas. v.1, n. 1. p. 21-39. 2007.

GUIMARÃES, M. Carreira e remuneração dos profissionais do magistério público do município de Breves-PA. 2015. 147p. Dissertação (Mestrado em Educação) - Universidade Federal do Pará, Belém, 2015.

GURGEL, Rogério Fernandes; Júnior, Luiz Sousa. Uma análise de planos de cargos, carreiras e remuneração do magistério da educação básica pública no Brasil. Fineduca - revista de Financiamento da Educação, Porto Alegre, v.3, p. 1-18, 2013. Disponível em: < http://seer.ufrgs.br/index.php/fineduca/article/ download/58391/34962>. Acesso em 17 fev. 2018

GUTIERRES, Dalva V.G. (Coord.); CARVALHO, F; JACOMINI, M; BRITO, V. Planos de Carreira de Professores da Educação Básica em Estados e Municípios Brasileiros no Contexto da Política de Fundos - FT-PCCR. In: Remuneração de Professores de Escolas Públicas de Educação Básica: configurações, impasses, impactos e perspectivas. Relatório de Pesquisa. OBEDUC, (CEPPPE)-FEUSP, São Paulo: USP, 2013.

PINO, Ivani Rodrigues. A trama da LDB na realidade política Nacional. Jornal da Educação. Educação e Sociedade. n. 41, abr. p. 156-185, 1992. 
ROCHA, Maria da Consolação. Políticas de valorização do magistério: remuneração, planos de carreira, condições de trabalho - uma análise da experiência em Belo Horizonte. 2009. 393p. Tese (Doutorado em Educação) Universidade de São Paulo, São Paulo, 2009

RODRIGUES Gonçalves, Sebastião. Movimento operário e Estado: a APPSindicato - a organização e as lutas dos trabalhadores na educação da rede pública estadual do Paraná. 2007. 138 p. Dissertação (mestrado em Educação) - Universidade Federal do Paraná. Curitiba, 2007.

TORRICELLA, F; J. M. Avaliação do desempenho e carreira docente: um estudo em cinquenta países da América e Europa. In: BALZANO, Sônia. (Org.). O desafio da profissionalização docente no Brasil e na América Latina. Brasília, DF: CONSED, UNESCO, 2007.

MARGARITA VICTORIA RODRÍGUEZ possui graduação em Licencia tura en Ciencias de La Educación - Universidad Nacional de Luján (1989) e doutorado em Filosofia e História da Educação pela Universidade Estadual de Campinas (1996). Atualmente é professora da Universidade Federal de Mato Grosso do Sul (UFMS). Pós-doutorado em História da Educação pela Universidade Federal de Minas Gerais. E-mail: poroyan@uol.com.br

DALVA VALENTE GUIMARÃES GUTIERRES possui graduação em Pedagogia pela Universidade Federal do Pará (1989), mestrado em Educação pela Universidade Federal do Pará (2005) e doutorado em Educação pela Universidade Federal do Rio Grande do Sul (2010). É professora Associada da graduação e da pósgraduação em Educação (Mestrado e Doutorado) da Universidade Federal do Pará e foi Diretora adjunta do Instituto de Ciências da Educação da Universidade Federal do Pará de 2014 a 2018. E-mail: dalva.valente@gmail.com

JORISMARY LESCANO SEVERINO é Mestre em Educação pela Universidade Federal de Mato Grosso do Sul. Graduada em Pedagogia - Licenciatura (Habilitação em Anos Iniciais e Educação Infantil) pela mesma universidade. Atualmente é doutoranda em Educação pela Universidade Federal de Mato Grosso do Sul e participa da linha de pesquisa: História, Políticas e Educação. E-mail: jorismary_lescano@hotmail.com 